\title{
Preparation, properties and behaviour of protein microparticles in salt containing dispersions
}

\author{
Alev Emine Ince Coskun and Semih Otles* \\ Department of Food Engineering, Ege University, Bornova, Izmir, Turkey
}

\begin{abstract}
This review focuses on the preparation of protein microparticles, considering especially whey proteins. Different production methods, such as heat-induced and coldinduced, could yield different characteristics of particles from each other. Behavior of microparticles discussed at different sizes of particles, at different temperature of the system, at different $\mathrm{pH}$ and salt conditions. Therefore functional, colloidal and rheological behaviors of dispersions including protein microparticles were also addressed. Finally, possible use areas of protein microparticles were explained.
\end{abstract}

\section{Introduction}

Microparticulation is a way of structuring different types of proteins in terms of their size, $\mathrm{pH}$, concentration or surface properties. Protein microparticles can be used for emulsifying, foaming, texturizing, adding functionality or controlled delivery systems [1]. Although there are many different types of proteins that can be used in microparticulation, dairy proteins such as caseins and whey proteins were commonly used and investigated in literature [2,3]. This review mainly focuses on the properties of milk proteins at different environmental conditions such as $\mathrm{pH}$ or salt concentration.

Microparticulation includes mainly the gelation of proteins in a confined geometry via different routes. In the first part of this review, different ways of protein particle formation will be discussed. In the second part mechanisms of particle formation will be explained considering the water content of particles. For example, physical and chemical differences at a $\mathrm{pH}$ value of close to $\mathrm{pI}$ or away from the $\mathrm{pI}$ during the production of protein particles will be explained. Colloidal behavior of protein particles in dispersions or at interfaces, especially when the salt is present will be explained in third part. Similarly, rheological behavior of protein particles in the presence of salt at different conditions will be the subject of fourth part. In the last part, current situation of microparticulated proteins in food industry and possible applications will be explained.

\section{Preparation of microparticulated proteins}

Aggregation or gelation of proteins is used to make protein particles to have a better control over the physicochemical properties. The gelation of whey proteins mainly includes an unfolding step, which allows the reactive groups of amino acids to rearrange. After this step, peptide chains interact through hydrophobic interactions, hydrogen bonding, electrostatic interactions, disulfide bridges and/or van der Waals interactions depending on the applied process [4]. As a result, rearrangement of proteins occurs, and the gel is formed.

\section{Heat-induced gelation}

Heat-induced gelation of proteins is the most commonly used method to make particles from globular proteins, especially from whey proteins [5-8]. Whey protein, a mixture of beta-lactoglobulin, alpha-lactalbumin, bovine serum albumin and immunoglobulins, has denaturation temperature around $60^{\circ} \mathrm{C}$, above which the reactive groups of amino acids become free and make the reformation possible via hydrophobic interactions, hydrogen bonding and disulfide bridges [6]. As disulfide bonds are mostly responsible for irreversible aggregation; stable aggregates can be formed. The size of aggregates, which can indeed be called as particles, depends on the heating time and temperature [9].

A protein-based fat substitute, known as Simplesse, was explained to be produced by an internationally patented process called "microparticulation", including heating and blending process at the same time. Milk and/or egg proteins were used to create $0.1-2.0 \mu \mathrm{m}$ sized particle gels. This size range of particles does not create grittiness perception after processing or swelling of the particles. Simplesse was used in several deserts and dairy products as a fat substitute, so the perceived creaminess was an important parameter [10].

In another study, Zhang and Zhong [3] used native whey proteins to make nm-sized particles which have better heat stability than the native protein. In their method, a native protein solution dispersed in an oil phase including surfactant, by adding the protein solution drop wise into the oil phase. After stirring for a while on a magnetic stirrer, emulsion was heated to $90^{\circ} \mathrm{C}$, above the denaturation temperature of whey proteins $\left(60^{\circ} \mathrm{C}\right)$, for $20 \mathrm{~min}$. At this step, proteins created a network inside the water phase in emulsion; irreversible aggregation occurred, and therefore hard particles were being formed. Heat treatment was followed by a cooling step and then particles were obtained using centrifuge. To remove the remnants of oil, washing step with ethanol was applied before further analyzing the particles. The

${ }^{\star}$ Correspondence to: Semih Otles, Department of Food Engineering, Ege University, Bornova, Izmir, Turkey, E-mail: semih.otles@ege.edu.tr

Key words: protein, microparticle, dispersion

Received: January 04, 2018; Accepted: January 25, 2019; Published: January 29, 2019 
average diameter of produced particles was below $100 \mathrm{~nm}$; therefore, a transparent dispersion could be obtained.

\section{Cold-induced gelation}

Cold-induced gelation mostly include electrostatic interactions between the proteins and generally used as a combination of heating step. In cold set gelation, aggregate formation can be achieved via different methods such as acidification $[2,11,12]$, salt addition $[9,13$ 16], or enzymatic crosslinking [17-20]. Heating step may be done before or after the aggregate formation to gel the particles and make them insoluble [8]. For instance, Schmitt and co-workers [8] induced the aggregate formation from whey proteins by changing the $\mathrm{pH}$ and then these aggregates were gelled by heating. Alternatively, Alting and co-workers [21] used a preheating step to create soluble $\beta$-lactoglobulin aggregates, and then gelled these aggregates by acidification.

Proteins have a net charge, which keeps them separate via electrostatic repulsion, unless they are at the iso-electric point (pI). At the pI, overall charge of the proteins is zero, therefore there is no repulsion between proteins. When the repulsive force is decreased or totally inhibited by bringing the $\mathrm{pH}$ close to the $\mathrm{pI}$, proteins start to form aggregates. For most of the proteins, $\mathrm{pI}$ is reached by acidification. Acidification can be done using either acid solutions $[2,11]$ or acidifying agents, such as glucono- $\delta$-lactone (GDL) [22,23]. For instance, sodium caseinate particles were obtained in a two-step emulsification process using GDL as acidifying agent [24]. However, as the electrostatic forces were the main forces for particle formation, NaCas particles were stable only in a narrow range of $\mathrm{pH}$. For whey protein particle formation at lower $\mathrm{pH}$ values ( $\mathrm{pH}$ 3-5) than $\mathrm{pI}$, rod-like particles were obtained [25], whereas at higher $\mathrm{pH}$ values it was possible to form spherical particles [26].

Enzymatic cross-linking of proteins is an alternative method for cold-set gelation of proteins. Most commonly used cross-linking enzyme is transglutaminase that functions through an acyl transfer mechanism in proteins involving a glutamine residue acid as an acyl donor and a lysine residue as an acyl acceptor [17,19,27].

\section{Factors affecting the functional properties of micropar- ticulated proteins}

Particle formation depends on many different parameters, such as protein source or gelation mechanism. Therefore, the stability of particles changes against swelling, hydration, or falling apart with respect to different physical and environmental factors will be different. Here, size of the particles, temperature, $\mathrm{pH}$ and salt effect on particles are discussed as examples.

\section{Size of particles}

In literature, there are many researches on the properties of different sized-particles of biological origin, such as proteins or starch $[28,29]$. In these studies, particles from a few nm to a few hundred $\mu \mathrm{m}$ were produced via different methods. For instance, in a study on the gelling behavior of yogurts, small protein particles were found to participate in gel network structure more efficiently than the larger ones. The reason was explained as the higher surface reactivity of small protein particles, thereby increasing the interaction potential of the native proteins present. When larger protein particles were used in yogurt formation, a higher syneresis was observed upon storage, which was taken as an indication of no participation of larger particles in network formation [29]. In another study stability of foams and emulsions with different particles was widely studied [28] and reported that the polydispersity and shape of particles had more importance instead of the size of the particles. This phenomenon is actually related to the Pickering effect on the stabilization, which is about the particle-stabilized emulsions or foams.

In Pickering emulsions or foams, the hydrophobicity, contact angle and wettability of particles, which are affected from the chemistry and shape of particles, are important. In addition, irregularity of particle shape was reported to have a positive contribution to stabilize foams and emulsions, most probably due to a good surface coverage [28].

Functional properties of particles such as solubility, gel strength or foaming ability were found to be affected from the particle size; however, particle size was not the only dominant parameter playing role [30]. As most of the time density, shape and/or the surface structure of particles are changing together with their size, interpretation of results as a combination of parameters would be more reliable.

\section{Heat stability of particles}

Heat stability of whey protein particles was found to be higher than the native proteins in different studies $[3,31]$. Native protein solution and particle dispersion were compared to each other by heating them above the denaturation temperature of proteins. Native protein solution formed a gel upon heating, whereas particle dispersion stayed as liquid [31]. This result indicated that protein particles can be good candidates in food products undergoing thermal treatment and in functional high protein containing foods.

Although protein particles have increased heat stability, Sağlam and co-workers [26] showed that the WPI particles produced at $\mathrm{pH} 6.8$ showed swelling upon heating, which indicated the heat instability. At the $\mathrm{pH}$ of 6.8, proteins had a net charge during gel formation; therefore, the gel had an open structure. Although the exact mechanism is still not known, these particles were shown to swell upon heating. The reason was attributed to the incomplete denaturation or shuffling of network strands [26], however these were not confirmed.

In another study, water holding capacity (WHC) of whey protein particles about $80 \mu \mathrm{m}$ in diameter produced via heating a protein solution were investigated [1]. They reported that an increase in WHC of particles upon heating the dispersions at higher temperatures. For instance, heating at $60^{\circ} \mathrm{C}$ and $90^{\circ} \mathrm{C}$ yielded higher water holding compared to heating at $30^{\circ} \mathrm{C}$. However, heating at $90^{\circ} \mathrm{C}$ for prolonged times was found not to have a significant effect on WHC of particles. This finding could be related to the degree of denaturation of native proteins, which could also affect the WHC of proteins.

\section{$\mathrm{pH}$ of the medium and the $\mathrm{pH}$ of the particles}

Changing $\mathrm{pH}$ of the dispersion medium changes the electrostatic interactions between proteins. Proteins can form denser aggregates at their $\mathrm{pI}$ values, as there is no repulsion between them; whereas if the gelation of particles is done away from the pI, then the network structure may be loose due to the repulsive forces between the proteins.

When particle formation was done only by changing the electrostatic interactions, then the particles would be slightly stable over a $\mathrm{pH}$ range. For instance, $\mathrm{NaCas}$ particles were produced at $\mathrm{pH} 3.5$, which was close to the $\mathrm{pI}$ (4.6), and they were only stable between $\mathrm{pH} 3$ and $\mathrm{pH}$ 5. The dispersion of these particles was stable even a narrower $\mathrm{pH}$ range, as the $\mathrm{pI}$ was reached at 4.6. Outside $\mathrm{pH} 3$ and $\mathrm{pH} 5$, particles were falling apart due to strong electrostatic repulsion [24].

In another study, whey protein particles produced at $\mathrm{pH} 5.5$, close to the $\mathrm{pI}$ of the proteins (5.1), by heat-induced gelation, were found 
to have a better stability over a wider $\mathrm{pH}$ range compared to the particles produced at $\mathrm{pH} 6.8$ [26]. As the protein particles produced at the pI had a denser network structure, stability of them against $\mathrm{pH}$ change and also heating was higher than the particles produced away from the pI. The gelation mechanism of whey proteins includes hydrophobic interactions and disulfide bonds via heating, which were not taken place in the gelation mechanism of $\mathrm{NaCas}$ particles. So, here the stability of WPI particles against changing $\mathrm{pH}$ and heating should only be compared between WPI particles prepared at $\mathrm{pH} 5.5$ and $\mathrm{pH}$ 6.8 .

\section{Salt type and concentration in the medium}

Addition of salt changes the net charge of proteins, which is a similar effect with acids; however, the mechanism is different from the $\mathrm{pH}$-induced aggregation. Salt ions screen the charges of proteins, which are responsible for the repulsive forces. As the repulsive forces decrease between proteins, they start to aggregate.

Different salt ions may affect the proteins at different strength. For instance, if the salt ions are monovalent, the screening of charges occurs; whereas if the salt ions are multivalent besides screening, there are additional effects, such as salt bridge formation or specific ion effect $[7,32]$. Therefore, multivalent ions are more effective in the aggregation of proteins and thus the minimum concentration to induce aggregation is lower than that of monovalent ions [33]. Stability and integrity of the protein particles thus depends not only on the concentration but also on the valence of the ions [34].

In the study of Zhang and Zhong [3], the size of whey protein particles was reported not to be affected by the $\mathrm{NaCl}$ concentration $(0$ $400 \mathrm{mM}$ ). However, larger WPI particles, a few $\mu \mathrm{m}$ in diameter, were reported to show shrinking with increasing concentrations of $\mathrm{NaCl}$ up to $500 \mathrm{mM}$ [24]. The reason was attributed to the screening of charges by salt ions as a result of decreased electrostatic repulsion at increasing ion concentrations. It was also noted that, changing $\mathrm{pH}$ of the medium using an acid solution had a stronger influence on the electrostatic interactions between the proteins compared to the changing the ionic strength with monovalent ions.

Another study investigating the hydration properties of casein micelles in salt solutions showed that increasing concentration of salt ions increased the hydration of casein micelles [35]. Casein micelles, without any salt addition, were spherical and around $150 \mathrm{~nm}$ in diameter. When salt is added, depending on the valence and concentration of the salt; shape, size and integrity of micelles changed. For instance, addition of $\mathrm{CaCl}_{2}$ increased the micelle size up to $500 \mathrm{~nm}$, probably because of coagulation. As a result of binding of ions at the surface of casein micelles, water molecules also reoriented according to the bound ions, thereby changing the hydration properties. If the coagulation is not extensive and micelles or particles could stay as separate entities, ions may increase the hydration of particles. However, if there is coagulation that decreases the surface area contacting with water, then hydration of particles may not be possible.

Interaction of salt ions with proteins were widely studied, especially in the case of preparation of protein particles via cold gelation [34,3637], however the study on interaction of salt ions with particulated proteins is limited [38]. Therefore, in this sense the investigation of interaction of salt ions with protein particles, assuming that they behave as hard or soft colloidal particles, may still be an open area.

\section{Colloidal behavior of microparticulated proteins in salt solutions}

Most of the time, protein particles behave like colloidal particles and they can be stabilized against coagulation by changing the surface properties. For instance, increasing the electrostatic or steric repulsive forces through changing $\mathrm{pH}$, adding salt, or coating the particles with polymers prevents the approaching of particles to each other, thereby preventing the coagulation [39]. Stability against aggregation or sedimentation and colloidal behavior of non-food grade particles, such as latex or styrene, in the presence of different salts were studied previously [40]. Studies on food grade particles in the presence of salts are still limited due to their unique properties depending on the fabrication method [38]. Food grade particles can be regarded as soft particles, as there is a network structure in a confined geometry. Therefore, density and strength of this network, physical and chemical interactions in the network, surface structure and porosity of the particles are all important for determining the interactions with the environment.

Hard colloidal particles in salt solutions showed different behaviors depending on the salt type and concentration [41]. Here salt type indicates the different valence of cations. For monovalent and divalent salts, screening of charges occurs; for multivalent ions, beyond screening, charge neutralization may occur depending on the ion concentration through adsorption of oppositely charged ions on the surface of the particles. When the concentration of ions is enough to neutralize all the charged patches on the surface of the particles, that is where the critical coagulation concentration is reached; particles start to coagulate as the repulsive forces are diminished.

Soft colloidal particles have different properties than the hard ones. Porous structure and swelling ability of soft particles change the behavior in salt solutions. For example, the maximum volume fraction of the particles for a stable dispersion in the case of soft ones was found to be lower than that in the case of corresponding rigid particles. As a theoretical approach, the reason was attributed to the smaller energy barrier for two interacting colloids, which includes the electrical and van der Waals energy, for the soft particles than that for the rigid particles. Salt ions change the properties of hard particles surfaces, whereas ions may penetrate into the soft particles through the pores on the surface. The strength of gel network inside the particles could vary due to this penetration. Therefore, the colloidal stability of particles changes against swelling, falling apart or shrinking.

\section{Rheological behavior of microparticulated protein dis- persions in salt solutions}

Soft protein particles are affected from its environment. Salt ions are able to alter the behavior of particles in two different ways. One of them is changing the electrostatic interactions between the particles. In this case protein particles may act as hard colloidal particles and the electrostatic interactions occur at the surface of the particles. In the first case, if the changes in repulsive forces occur at the surface and particles behave as hard particles, a decrease in the repulsive force would yield coagulation of particles. Larger particles are formed, and phase separation can be seen depending on the volume fraction of particles and ionic strength. The other way is changing the interactions inside the particle, which is within the gel network structure. In this case, due to increasing or decreasing repulsive forces, gel network structure is changing. As a result of the change, particles may shrink 
or swell, thereby changing the physical properties of particles, such as size, density, or hardness [24]. In both cases, if electrostatic repulsion is high, viscosity of the dispersion tends to increase. When electrostatic repulsion is between the particles, their effective volume fraction would increase in dispersion, which possibly increases the viscosity of the dispersion. Similarly, when electrostatic repulsion is inside the gel network, particle tends to swell, which also increases the viscosity.

The flow behavior of soft hydrogel particles containing $\mathrm{NaCas}$ and pectin showed that increasing concentrations of $\mathrm{NaCl}$ upto $100 \mathrm{mM}$ decreased the viscosity of dispersions at constant shear rate, whereas $\mathrm{NaCl}$ concentrations from $100 \mathrm{mM}$ to $400 \mathrm{mM}$ increased the viscosities [25]. The reason was attributed to the changes in the effective volume fraction of particles, which depended on the porosity and shape of the particles. It was also indicated that higher salt concentrations could lead to thicker sediment layers, which also increased the viscosity of the dispersions. In the same study, hydrogel particle dispersions were reported to show shear-thinning behavior with increasing shear rate values. Alternatively, in another study, whey protein particles at high particle volume fractions were shown to exhibit shear-thickening behavior at high shear rate values, probably because of interaction of particles with co-solvents [24,42].

\section{Use of microparticulated proteins in foods}

Structural modifications of protiens, such as microparticulation, can be done either using only protein solutions or as a combination of different ingredients such as proteins and polysaccharides [43]. Such modifications allow particles having different physical or chemical properties, therefore reasons of use such particles in foods vary from increasing protein concentrations to be a fat replacer [38].

One example is the use of whey protein-based particles as a fat replacer in low fat mozzarella cheese [44]. An increase in the melting properties and total moisture content of the mozzarella cheese were also reported when whey protein-based particles were used. Using the same whey protein-based particles as fat replacer, other researchers produced low fat $(6 \%)$ and fat-free $(0.5 \%)$ ice creams [45]. According to the sensory panels, low fat ice cream was found to be comparable with the full-fat control sample, whereas fat-free ice cream was scored lower regarding the viscosity, smoothness and mouth coating properties. As a texture modifier whey protein particle were also used in low-fat yogurt manufacture together with native whey proteins [29]. A lower ratio of particles to native proteins resulted in higher creaminess and viscosity values, and lower syneresis.

Whey protein particles prepared via cold set gelation using GDL and via heat set gelation were used in gluten-free bread formulations as a texture enhancer [46]. Particle sizes have a large distribution from $100 \mathrm{~nm}$ to $100 \mu \mathrm{m}$. Proofing and baking of breads with protein particles indicated promising results in the formulation of gluten-free bread dough.

Another use of proteins is to produce capsules and shell materials for bioactive compounds, thereby creating encapsulated materials for controlled delivery [47]. For instance, at the isoelectric point of proteins, protein shell or protein particles are at their dense form, therefore they can keep the bioactive compound in or inside their structure. When these particles are away from this $\mathrm{pH}$, the repulsive forces in the network of the structure increase depending on the $\mathrm{pH}$ and thereby increasing the opening between the strands in network. As a result, the bioactive compound can release from the particle in a controlled way.
As potential applications of protein particles, production of high protein content medical drinks [24] or acidified milk drinks [24] were suggested. As proteins are susceptible to heat applications, such as aggregation, coagulation or gelation, above certain concentrations during manufacture of drinks, it is important to control the texture of the product. Viscosity increase could be detrimental for the selected products. Alternatively, acidification of drinks, milk products like kefir or fruit juices, could contain limited amount of native protein, whereas if proteins are included in particulated form, the concentration of protein in drinks can be increased without changing the textural and sensorial attributes of the product.

\section{Conclusion}

In this review, the importance of designed protein particles, their behavior and use areas were addressed. For the preparation of particles, mainly heat-induced or cold-induced methods were used. The combination of both methods was also used for particle preparation. $\mathrm{pH}$, gelling temperature and ionic strength were found to affect the hydration and swelling of particles; whereas size of the soft particles was found less effective on hydration properties compared to the size distribution or shape. The stability of particle dispersions was affected from the ionic strength of the solution. Colloidal and rheological behavior of particle dispersions was affected mostly from the hardness of the particles and the porous structure of the gel network. These physicochemical properties gave flexibility to such particles to be used in foods with different functional properties, such as texturizer, stabilizer or in encapsulation studies. Protein particles were already used in ice cream, yogurt and cheese and have potential to be used in medical and acidified milk drinks in future.

\section{References}

1. Purwanti N, Peters JPCM, van der Goot AJ (2012) Protein micro-structuring as a tool to texturize protein foods. Food and Function 4: 277-282.

2. Ruis HGM, Venema P, van der Linden E (2007) Relation between $p H$-induced stickiness and gelation behaviour of sodium caseinate aggregates as determined by light scattering and rheology. Food Hydrocolloids 21: 545-554.

3. Zhang W, Zhong Q (2010) Microemulsions as nanoreactors to produce whey protein nanoparticles with enhanced heat stability by thermal pretreatment. Food Chem 119: 1318-1325.

4. Dill KA (1990) Dominant forces in protein folding. Biochemistry 29: 7133-7155. [Crossref]

5. Mehalebi S, Nicolai T, Durand D (2008) Light scattering study of heat- denatured globular protein aggregates. Int J Biol Macromol 43: 129-135. [Crossref]

6. Moitzi C, Donato L, Schmitt C, Bovetto L, Gillies G, et al. (2011) Structure of $\beta$-lactoglobulin microgels formed during heating as revealed by small-angle X-ray scattering and light scattering. Food Hydrocolloids 25: 1766-1774.

7. Nicolai T, Durand D (2013) Controlled food protein aggregation for new functionality. Curr Opin Colloid Interface Sci 18: 249-256.

8. Schmitt C, Bovay C, Vuilliomenet AM, Rouvet M, Bovetto L (2011) Influence of protein and mineral composition on the formation of whey protein heat-induced microgels. Food Hydrocolloids 25: 558-567.

9. Phan-Xuan T, Durand D, Nicolai T, Donato L, Schmitt C, et al (2013) Tuning the structure of protein particles and gels with calcium or sodium ions. Biomacromolecules 14: 19801989. [Crossref]

10. Singhal RS, Gupta AK, Kulkarni PR (1991) Low-calorie fat substitute. Trends Food Sci Technol 2: 241-244

11. Lee WJ, Lucey JA (2010) Formation and physical properties of yogurt. AsianAustralian Journal of Animal Science 23: 1127-1136.

12. Xu J, Li T, Tao F, Cui Y, Xia Y (2013) Structure evolution of gelatin particles induced by $\mathrm{pH}$ and ionic strength. Microsc Res Tech 76: 272-281. 
13. Carr CW (1953) Studies on the binding of small ions in protein solutions with the use of membrane electrodes. III. The binding of chloride ions in solutions of various proteins. Arch Biochem Biophys 46: 417-423.

14. Curtis RA, Lue L (2006) A molecular approach to bioseparations: Protein-protein and protein-salt interactions. Chemical Engineering Science 61: 907-923.

15. Dumetz AC, Snellinger-O'brien AM, Kaler EW, Lenhoff AM (2007) Patterns of protein protein interactions in salt solutions and implications for protein crystallization. Protein Sci 16: 1867-1877. [Crossref]

16. Ginsburg A, Carroll WR (1965) Some specific ion effects on the conformation and thermal stability of ribonuclease. Biochemistry 4: 2159-2174.

17. Clare DA, Daubert CR (2010) Transglutaminase catalysis of modified whey protein dispersions. J Food Sci 75: 369-377. [Crossref]

18. Lorenzen PC (2007) Effects of varying time/temperature-conditions of pre-heating and enzymatic cross-linking on techno-functional properties of reconstituted dairy ingredients. Food Res Int 40: 700-708.

19. Nivala O, Mäkinen OE, Kruus K, Nordlund E, et al. (2017) Structuring colloidal oat and faba bean protein particles via enzymatic modification. Food Chem 231: 87-95.

20. Zhang W, Zhong Q (2009) Microemulsions as nanoreactors to produce whey protein nanoparticles with enhanced heat stability by sequential enzymatic cross-linking and thermal pretreatment. J Agric Food Chem 57: 9181-9189. [Crossref]

21. Alting AC, de Jongh HH, Visschers RW, Simons JW (2002) Physical and chemical interactions in cold gelation of food proteins. J Agric Food Chem 50: 4682-4689. [Crossref]

22. Andoyo R, Guyomarc'h F, Cauty C, Famelart MH (2014) Model mixtures evidence the respective roles of whey protein particles and casein micelles during acid gelation. Food Hydrocolloids 37: 203-212.

23. Lucey JA, van Vliet T, Grolle K, Geurts T, Walstra P (1997) Properties of acid casein gels made by acidification with glucono- $\delta$-lactone. 1 . Rheological properties. Int Dairy J 7: 381-388.

24. Ince Coskun AE, Saglam D, Venema P, van der Linden E, Scholten E (2015) Preparatiom, structure and stability of sodium caseinate and gelatin micro-particles. Food Hydrocolloids 45: 291-300.

25. Chung C, McClements DJ (2015) Controlling microstructure and physical properties of biopolymer hydrogel particles through modulation of electrostatic interactions. $J$ Food Eng 158: 13-21.

26. Saglam D, Venema P, de Vries R, van der Linden E (2013) The influence of pH and ionic strength on the swelling of dense protein particles. Soft Matter 9: 4598-4606.

27. Eissa AS, Khan SA (2005) Acid-induced gelation of enzymatically modified, preheated whey proteins. J Agric Food Chem 53: 5010-5017.

28. Lam S, Velikov KP, Velev OD (2014) Pickering stabilization of foams and emulsions with particles of biological origin. Curr Opin Colloid Interface Sci 19: 490-500.

29. Torres IC, Mutaf G, Hofmann Larsen F, Ipsen R (2016) Effect of hydration of microparticulated whey protein ingredients on their gelling behavior in a non-fat milk system. J Food Eng 184: 31-37.

30. Onwulata CI, Tomasula PM (2006) Improving functionality of whey protein concentrates from different sources. Int J Dairy Sci 1: 1-8.
31. Saglam D, Venema P, de Vries R, van der Linden E (2014) Exceptional heat stability of high protein content dispersions containing whey protein particles. Food Hydrocolloids 34: 68-77.

32. Guldbrand L, Jönsson B, Wennerström H, Linse P (1984) Electrical double layer forces A Monte Carlo study. J Chem Phys 80: 2221-2228.

33. Lyklema J (2014) Coagulation by simple multivalent counterions. Colloids Surf A Physicochem Eng Asp 460: 468-472.

34. Kundu S, Chinchalikar AJ, Das K, Aswal VK, Kohlbrecher J (2014) Mono-, di- and trivalent ion induced protein gelation: Small-angle neutron scattering study. Chem Phys Lett 593: 140-144

35. Hussain R, Gaiani C, Scher J (2012) From high milk protein powders to the rehydrated dispersions in variable ionic environments: A review. J Food Eng 133: 486-503.

36. Kharlamova A, Nicolai T, Chassenieux C (2018) Calcium-induced gelation of whey protein aggregates: Kinetics, structure and rheological properties. Food Hydrocolloids 79: $145-157$.

37. Xu HN, Liu Y, Zhang L (2015) Salting-out and salting-in: competitive effects of salt on the aggregation behavior of soy protein particles and their emulsifying properties. Soft Matter 11: 5926-5932.

38. Chung C, Degner B, McClements DJ (2014) Development of reduced-calorie foods: Microparticulated whey proteins as fat mimetics in semi-solid food emulsions. Food Res Intern 56: 136-145.

39. Wagoner TB, Foegeding EA (2017) Whey protein-pectin soluble complexes for beverage applications. Food Hydrocolloids 63: 130-138.

40. Trefalt G, Szilagyi I, Tellez G, Borkovec M (2017) Colloidal stability in asymmetric electrolytes: Modifications of the Schulze-Hardy rule. Langmuir 33: 1695-1704.

41. Cao T, Szilagyi I, Oncsik T, Borkovec M, Trefalt G (2015) Aggregation of Colloidal Particles in the Presence of Multivalent Co-Ions: The Inverse Schulze-Hardy Rule. Langmuir 31: 6610-6614. [Crossref]

42. Drapala KP, Mulvihill DM, O'Mahony JA (2018) A review of the analytical approaches used for studying the structure, interactions and stability of emulsions in nutritional beverage systems. Food Structure 16: 27-42.

43. Ahmed KF, Aschi A, Nicolai T (2018) Formation and characterization of chitosanprotein particles with fractal whey protein aggregates. Colloids Surf B Biointerfaces 169: 257-264.

44. McMahon DJ, Alleyne MC, Fife RL, Oberg CJ (1996) Use of fat replacers in low fat Mozzarella cheese. J Dairy Sci 79: 1911-1921.

45. Ozcan Yilsay T, Yilmaz L, Akpinar Bayizit A (2006) The effect of using a whey protein fat replacer on textural and sensory characteristics of low-fat vanilla ice cream. Eur Food Res Tech 222: 171-175.

46. van Riemsdijk LE, van der Goot AJ, Hamer RJ, Boom RM (2011) Preparation of gluten-free bread using a meso-structured whey protein particle system. J Cereal Sci 53: $355-361$.

47. Ariyarathna IR, Karunaratne DN (2015) Use of chickpea protein for encapsulation of folate to enhance nutritional potency and stability. Food and Bioproducts Processing 95: 76-82.

Copyright: C2019 Coskun AEI. This is an open-access article distributed under the terms of the Creative Commons Attribution License, which permits unrestricted use, distribution, and reproduction in any medium, provided the original author and source are credited. 